\title{
Strategies on Fostering English Autonomous Learning Ability under the Influence of Mobile Multimedia
}

\author{
Huanhuan Ren ${ }^{1,}$, Chi Ma ${ }^{2, b}$ \\ ${ }^{1}$ Teaching and Research Institute of Foreign Languages, Bohai University, Jinzhou, 121013, China \\ ${ }^{2}$ Jinzhou Institute of Forestry Research, Jinzhou Forestry Bureau, Jinzhou, 121013, China

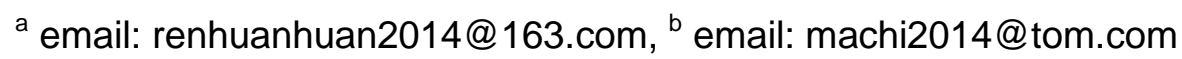

Keywords: Strategies; English Autonomous Learning Ability; Mobile Multimedia

\begin{abstract}
With the rapid advance in technologies of mobile multimedia and the Internet, mobile multimedia have found their way in people's life, especially in the educational field, and they have shown their tremendous superiority over traditional one-way communication in English language learning. Organic connection of learning space and learning time, and seamless integration of high technologies in learning process are proposed as dominating principles of fostering English autonomous learning ability via mobile multimedia. Trainings on learning strategy should be articulated and undertaken in many programs aiming to promote students' English language proficiency and autonomous learning ability in English learning.
\end{abstract}

\section{Introduction}

With the rapid advance in technologies of mobile multimedia and the Internet, the application of mobile multimedia has entered a new era in people's life, especially in the educational field. Specifically, mobile multimedia have shown their tremendous superiority over traditional one-way communication in language learning and instruction. Mobile multimedia can modernize language learning environment with better interfaces and visual images, and make language learning materials vivid, dynamic and collaborative through non-linear structure. Under such circumstance, a question concerning with autonomous learning in language learning is brought out, and that's, how to foster English autonomous learning ability under the influence of mobile multimedia. In this thesis, we try to argue for dominating rules and specific strategies of fostering English autonomous learning ability via mobile multimedia, so as to promote students' English language proficiency and autonomous learning ability in English language learning.

\section{Literature Reviews on English Autonomous Learning Ability}

Views on learner autonomy. Despite multiple perspectives and different paradigms of learner autonomy, there is some agreement on a large number of issues on the term. It's commonly believed that the purpose of autonomous learning is to encourage students to move from teacher-directed learning (in which knowledge of the language and skills are imparted by the teacher) to self-directed learning (in which the ability to learn independently are cultivated in addition to language knowledge and skills). Autonomous learning refers to the capacity to take charge of one's own learning, or say, students are seen as being able to assume a more active and participatory role. However, learner autonomy is a relative concept rather than an absolute concept which has set clear boundaries for itself. As Benson observed, absolute autonomous learning and non-autonomous learning don't exist, and most of learning is between those two points[1]. Autonomous learners are self-regulation learners who can take responsibility for their own learning, defining their own objectives, knowing how to use language materials effectively, organizing time for learning, choosing and developing learning strategies, monitoring the procedure of acquisition properly and evaluating what has been acquired[2]. It's advisable to cultivate language learners' autonomous learning ability in line with their respective needs and situation, and at the same time teachers need to relinquish some of their control over learners by allowing students to experience responsibility 
for their learning.

English autonomous learning. Since the late 1970s to the mid-1980s, English began to be taught at all levels of the educational sector across China. In 2007, College English Curriculum Requirements, one requirement of which is to remold the existing unitary teacher-centered pattern of language teaching, points out that the goal of English instruction is "to cultivate students' autonomous learning ability as the center, to make full use of modern education technology, to construct individualized college English teaching mode, and to improve students' comprehensive ability to use English, especially listening and speaking ability."[3] The acquisition of learner autonomy is thereby regarded as a crucial element of the college English teaching reform across the country. Since then, there has been a growing interest in the practice of learner autonomy in English language learning, and learning context or setting for language learning in which learners develop their skills, has been actively built and maintained by language instructors in universities and colleges. The student is encouraged to be totally responsible for all of the decisions concerned with his (or her) learning and implementation of those decision in English learning, and the instructor is supposed to put students at the center of the learning process and attaches great importance to students' needs, so that learners' English attributes and skills can be acquired and used in a self-directed manner.

English learner autonomy via mobile multimedia. Language learning is closely related to media. With the rapid advance in technologies of mobile multimedia, mobile multimedia have found their way in English autonomous learning. The traditional blackboard approach is gradually giving way to this more interactive, flexible, and personalized one. Mobile multimedia avail learners of pictures, sounds, video clips etc., and transmit information quickly and accurately. Though mobile multimedia enjoy only a short history of no more than two decades, and once arouse a bitter controversy among the educators and language teachers, mobile multimedia have demonstrated their formidable vitality, especially in the realm of English language learning[4]. It can also be found in College English Curriculum Requirements, which states that, "network-based multimedia instruction will be a new approach to college English instruction, and at the same time it will be the development orientation of the reform of English teaching and learning in colleges and universities"[5]. Learner autonomy is more likely to be cultivated via mobile multimedia, and this flexible and personalized learning approach is conducive to learners' development by providing language learners with an contextual and engaging learning environment.

\section{Dominating Principles of fostering English Autonomous Learning Ability}

Organic connection of learning space and learning time. Fostering English autonomous learning ability is not an easy job which is concerning with the organization of each stage in learning process, but a three-dimensional framework that has to combine the learning space and learning time in the learning process. It goes beyond the physical space of learners (i.e. invisible network terminal, including two parts which are curricular and extracurricular, or in-class and out-of-class) and information space (i.e. the context of information, consisting of two parts which are online and offline), to build a multi-dimensional autonomous learning model rich in resources and possibilities. The gap among different subspaces divided by physical space and information space can be covered by mobile multimedia, so as to achieve a friendly and constructive learning environment. The organic connection is also true to the horizontal integration of learning (i.e. the integration of physical space and information space) in the EFL learning process and the vertical integration of learning (i.e. the integration of different autonomous learning stages). They don't exist in isolation, but complement each other in language learning. In addition, other spaces such as social space, power space, etc., should also be considered in the organic connection of learning space and learning time, and they exert positive effects in the overall learning process.

In summary, the organic connection of learning space and learning time involves the horizontal integration of learning and the vertical integration of learning, and the connection of each elements in the horizontal integration of learning and the vertical integration of learning as well. As the advance in learning space and learning, the connection of space and time expand accordingly and 
continuously.

Seamless integration of technologies. The pervasive technology of mobile multimedia in English autonomous learning is an essential environmental factor which plays a critical role in fostering English autonomous learning abilities. Specifically speaking, 'high tech' can be divided into hardware technologies (e.g. smart mobile devices, 4G wireless networks etc.) and software technologies (e.g. intelligent software, context recognition technology, etc.). Hardware technologies should be seamlessly integrated into autonomous learning environment, so as to make the learning situational, individual and interactive, and provide a real and natural environment for language learners. What's more, software technologies should also be deeply integrated into language learning in line with the educational ideas (e.g. humanism, constructivism, etc.). It's targeted to help language learners get access to instant communication and rich exchange in English autonomous learning and thereby help promote students' ability to learn independently.

In short, the seamless integration of technologies involves the seamless integration of hardware technologies and learning context, and the natural integration of software technologies and learning context as well. The integration should be as timely, effective and natural as possible, so as to give language learners considerable freedom and convenience in language learning.

\section{Concrete Strategies on Fostering English Autonomous Learning Ability under the Influence of Mobile Multimedia}

Consciousness of motivation, especially intrinsic motivation. Why do learners learn? Each learner should have consciousness of the starting point of English language learning. Language learners should study out of their psychological needs rather than their utilitarian needs (i.e. exam), and that's to say, intrinsic motivation that's driven by an interest or enjoyment is encouraged instead of extrinsic motivation that comes from influences outside of the individual. A variety of approaches may be needed to motivate students' autonomous learning ability via mobile multimedia, as mobile multimedia can bring about a brand-new learning experience, quite possibly positive learning experience. Rewards and punishments do play a role in fostering English autonomous learning ability, but the effect is not long-lasting and self-sustaining. With appropriate intervention of mobile multimedia, students' positive motivation can be enhanced and thereby language learners are more likely to engage into English language learning.

Vision of specific objectives of English learning. Learning motivation helps students get to know where to start while learning objective helps students get to know where to go. Having a good picture or vision of different learning processes and ultimate goals is beneficial for learners' English language proficiency and English autonomous learning ability. Good objectives should never be too general or too big for learners, therefore objectives have to be broken into components in order to make each objective specific and manageable for language learners, for example English language skills are made up of listening, speaking, reading and writing, and specific requirements on each skill are good guidance for students in their language learning. Specific objectives can be vividly outlined with the help of mobile multimedia, and the gap between the future objective and the near reality can be simultaneously presented to each individual for further reflection in learning process.

Interaction with environment rich in information. Leaning is an active interaction with the environment[6]. How to live and learn in the learning environment is a big concern for language learners. The challenge that every language learner is faced with is information explosion as opposed to information scarcity. That's to say, the information obtained through mobile multimedia is like a virtual library or bank of information covering all aspects. It's advised that learners possess the ability to figure out useful information and useless information, and the ability to utilize them effectively and efficiently. Therefore the teacher should cultivate students' information literacy by guiding learners to explore natural, authentic and fresh language materials on their own via mobile multimedia. Afterwards, the instructor is in a position to make high-hit online resources comprehensive, sharable and interactive among students, so that peer students can acquire the relevant language knowledge or skills to the maximum extent. Besides, a great deal of information as to how to learn English language should be accessible to students, and language learners exercise 
and test the information in their independent learning processes.

Incentive plans via mobile multimedia. How to bring the initiative and the autonomy of learners into full play? Incentive plans can help in the first place. It's required that instructors take comprehensive account of students' technical, psychological, socio-cultural and critical personalities[7] and figure out the best approach of learning for each individual one. What kind of obstacles may come up and what kind of actions can save the bad situation? Specifically, two things should be done by teachers with the help of mobile multimedia. Firstly, learning anxiety in the learning process should be observed and overcome through rich communication, especially real-time communication via mobile multimedia. Secondly, learners' confidence and initiative should be developed and strengthened to better student's performance. Various and flexible incentive dialogues can be carried out via mobile multimedia so that specific individual learning problems are more likely to be solved at their source. Efforts should be made by instructors to achieve collaboration and competition among peer students, and thus language learners can be highly engaged in their language learning.

Monitoring actions for desirable learning results. By using mobile multimedia, the monitoring process can be carried out by instructors at any time and at any place. Instructors are ought to make sense of their monitoring actions by connecting monitoring results of students with reflection and further learning of learners. In that case, inquiry, problem solving, active engagement and even critical thinking are more likely to take place. Teachers should assure that students are active participants in the development of their own understanding, or say that, learners are not only physically involved, but also engaged cognitively, psychologically, emotionally and intellectually. Moreover, language learning should occur in meaningful context or realistic situation with the help of instant communication and rich resources. Mobile multimedia, as a aid to create realistic situation, help learners construct their knowledge schemata and achieve optimum language learning results.

Optimization of the assessment system. A comprehensive, objective, scientific and fair assessment system is of vital importance to the achievement of English autonomous learning ability. The assessment strategies can be conducted from two directions, namely what to be assessed and how to assess. Firstly, learning process and learning outcomes should be put equal emphasis in the assessment process, and it's equal to say that both summative assessment and formative assessment should be combined to facilitate language learners' abilities via mobile multimedia[8]. It’s advisable that autonomous learning ability be taken into account in the learning process. Secondly, traditional paper-and pencil test fails to assess the all-around abilities of language learners, especially English language learner autonomy. Therefore a new mobile-multimedia assisted assessment should take place to collect, synthesize and interpret information for the decision making of both instructors and learners. At the same time, observation, interview, portfolio can still find their way in the assessment process[9]. As for the participants in the assessment, peer assessment, self assessment and teacher assessment should be combined together in English instruction by language instructors to assess learners' overall abilities in English language learning.

\section{Conclusion}

There are many reasons for mobile multimedia to be applied into college English language learning, and fostering English autonomous learning ability is undoubtedly an important one of them. Autonomous learning ability is regarded as a key capacity needed for individuals to engage in various learning activities over their life time, and is generally accepted as a key educational goal in English learning. With mobile multimedia being taken into full consideration, individual learner can make dramatic stride in their English language autonomous learning. Specially, trainings on learning strategy via mobile multimedia should be articulated and undertaken in many programs aiming to achieve students' English language proficiency and English language learner autonomy. 


\section{Acknowledgement}

This work is part of the project of Research on the Cultivating Mechanism and Strategies for College English Autonomous Learning Ability via Mobile Multimedia, and the project of Development and Innovation Research on College English Learner Autonomy Mode in Ubiquitous Network Environment. This research was supported by the Fund of the Thirteenth Five-Year Plan of Education Sciences of Liaoning Province (Project No. JG16DB013), the fund of Liaoning Provincial Federation Social Science Circles (Project No. 2016lslktwx-01) and the fund of Liaoning Planning Office of Philosophy and Social Sciences (Project No. L15CWW001).

\section{References}

[1] Benson, P., Learner Autonomy[J]. TESOL Quarterly, Read and Write Periodical, 2012(8).

[2] Holec, H., Autonomy in Foreign Language Learning [M]. Oxford: Pergamon, 1981.

[3][5] Ministry of Education of the People's Republic of China, College English Curriculum Requirements[M]. Beijing: Higher Education Press, 2007.

[4] Pan Fei, A Study of College English Teaching Model in the Setting of Multimedia and Internet Technology[M]. Shanghai: Shanghai International Studies University, 2007.

[6] Ren Huanhuan, Connotation and Characteristics of Independent Study with Perspective of Educational Ecology[J]. Journal of Teaching and Management, 2016 (24).

[7] Ren Huanhuan, Gao Peng, Development of English Autonomous Learning Skill Rating Scale for College Students[J]. Journal of Liaoning University of Science and Technology, 2012 (02).

[8][9] Ren Huanhuan, Zhao Min, The Impact of Formative Assessment on Learner Autonomy in English Pedagogy[J]. Journal of Jiamusi Education Institute, 2012 (02). 